\title{
Review Article \\ Hepatitis C Virus in North Africa: An Emerging Threat
}

\author{
Mohamed A. Daw, ${ }^{1}$ Abdallah El-Bouzedi, ${ }^{2}$ Mohamed O. Ahmed, ${ }^{3}$ \\ Aghnyia A. Dau, ${ }^{4}$ and Mohamed M. Agnan ${ }^{5}$ \\ ${ }^{1}$ Department of Medical Microbiology, Faculty of Medicine, Tripoli University, P.O. Box 82668, Tripoli, Libya \\ ${ }^{2}$ Department of Laboratory Medicine, Faculty of Biotechnology, Tripoli University, P.O. Box 82668, Tripoli, Libya \\ ${ }^{3}$ Department of Microbiology and Parasitology, Faculty of Veterinary Medicine, Tripoli University, \\ P.O. Box 13662, Tripoli, Libya \\ ${ }^{4}$ Department of Surgery, Tripoli Medical Centre, Faculty of Medicine, Tripoli University, P.O. Box 82668, Tripoli, Libya \\ ${ }^{5}$ Department of Pharmacology, Faculty of Medical Technology, Algabal Algarbi University, P.O. Box 3321, Nalut, Libya
}

Correspondence should be addressed to Mohamed A. Daw; mohamedadaw@gmail.com

Received 6 April 2016; Revised 21 June 2016; Accepted 19 July 2016

Academic Editor: Anna Linda Zignego

Copyright (C) 2016 Mohamed A. Daw et al. This is an open access article distributed under the Creative Commons Attribution License, which permits unrestricted use, distribution, and reproduction in any medium, provided the original work is properly cited.

\begin{abstract}
Hepatitis C virus is a major public health threat associated with serious clinical consequences worldwide. North Africa is a unique region composed of seven countries that vary considerably in the predisposing factors to microbial diseases both historically and at the present time. The dynamics of HCV in the region are not well documented. The data are both limited and controversial in most of the countries in the region. In North Africa, the epidemiology of HCV is disparate and understanding it has been hampered by regional "epidemiological homogeneity" concepts. As the dynamics of HCV vary from country to country, context-specific research is needed. In this review, we assess studies performed in each country in the general populations as well as among blood donors and groups exposed to the HCV infection. The reported prevalence of HCV ranges from $0.6 \%$ to $8.4 \%$ in the Maghreb countries and is predominated by genotype 1 . In the Nile valley region, it ranges from $2.2 \%$ to $18.9 \%$ and is dominated by genotype 4 . In North African countries, HCV seems to be a serious problem that is driven by different vectors even in different geographical locations within the same country. Efforts should be combined at both the national and regional levels to implement efficient preventive and treatment strategies.
\end{abstract}

\section{Introduction}

Hepatitis $\mathrm{C}$ virus (HCV) is one of the most important viruses. The dynamic nature of the virus, its transmission by various vectors, and the diversity of the subtypes are reflected in the epidemiology of hepatitis $\mathrm{C}$ infection. The global prevalence of anti-HCV has been estimated at 2.0\% (1.7-2.3\%) among adults and $1.6 \%(1.3-2.1 \%)$ for all ages. These percentages mean that there are about 115 million people infected with HVC, of whom about 104 million are adults [1]. The World Health Organization (WHO) recognizes viral hepatitis as a global health challenge from which no country, rich or poor, is spared. As hepatitis $\mathrm{C}$ virus infection is not preventable by vaccination, WHO urges member states to take action to improve surveillance, prevention, and access to screening and treatment at the national and regional levels [2].
Hepatitis $\mathrm{C}$ virus infection is a major public health concern particularly in African countries, which have the highest prevalence rates of $\mathrm{HCV}$ in the world (1-26\%) [3]. In Africa over 28 million people are chronically infected with HCV and it is difficult to speculate about current and future trends [4]. The prevalence of HCV varies from one African country to another. Comparison of the epidemiological status in different countries is difficult due to variations in diagnostic procedures, multiplicity of definitions of infection, and the use of different methods, as well as the time at which the epidemiological research was done [5].

Due to the great diversity in prevalence and modes of transmission, accurate epidemiological information on HCV infections is urgently needed to guide national and regional plans for prevention, treatment, and reduction of complications of the infection [6]. Accurate data are scarce for 
TABLE 1: Prevalence of HCV, development parameters, and genotype distribution in North African countries.

\begin{tabular}{|c|c|c|c|c|c|c|c|}
\hline \multirow[b]{2}{*}{ Countries } & \multicolumn{5}{|c|}{ Maghreb region } & \multicolumn{2}{|c|}{ Nile region } \\
\hline & Libya & Tunis & Algeria & Morocco & Mauritania & Egypt & Sudan \\
\hline Population (millions) & 6.42 & 11 & 35 & 32 & 3.5 & 82.5 & 44.6 \\
\hline Population density (people $/ \mathrm{km}^{2}$ ) & 04 & 71 & 16 & 76 & 04 & 90 & 22 \\
\hline Literacy rate $(\mathrm{M} ; \mathrm{F})$ & $\begin{array}{c}99.95 \% \\
(99.97 ; 99.93)\end{array}$ & $\begin{array}{c}98.06 \% \\
(98.35 ; 97.76)\end{array}$ & $\begin{array}{c}95.59 \% \\
(95.65 ; 95.52)\end{array}$ & $\begin{array}{c}83.19 \% \\
(90.10 ; 75.87)\end{array}$ & $\begin{array}{c}62.63 \% \\
(70.04 ; 54.98)\end{array}$ & $\begin{array}{c}91.12 \% \\
(93.42 ; 88.73)\end{array}$ & $\begin{array}{c}89.57 \% \\
(91.29 ; 87.81)\end{array}$ \\
\hline GNI (PPP US\$) & 16020 & 3720 & 4420 & 2770 & 2400 & 6120 & 2120 \\
\hline HDI (2010-2014) & 0.849 & 0.712 & 0.736 & 0.628 & 0.453 & 0.644 & 0.408 \\
\hline Country classification & $\mathrm{HI}$ & LMI & LMI & LMI & LI & LMI & LI \\
\hline \multicolumn{8}{|l|}{$\begin{array}{l}\text { Prevalence of HCV genotypes \& } \\
\text { subtypes }\end{array}$} \\
\hline 1 & $35 \%$ & $67 \%$ & $89 \%$ & $68 \%$ & ? & $5 \%$ & $5 \%$ \\
\hline la & la & la & la & la & & - & - \\
\hline $1 b$ & $1 b$ & $1 b$ & $1 b$ & $1 b$ & & - & - \\
\hline 2 & 14.2 & $13 \%$ & $9 \%$ & $30 \%$ & ? & $2 \%$ & $3 \%$ \\
\hline $2 \mathrm{a}$ & $2 \mathrm{a}$ & $2 \mathrm{a}$ & $2 \mathrm{a}, 2 \mathrm{~b}$ & $2 \mathrm{i}, 2 \mathrm{k}$ & & - & - \\
\hline 3 & $15 \%$ & $3 \%$ & $1 \%$ & - & $?$ & - & - \\
\hline 4 & $29.2 \%$ & $21 \%$ & $1 \%$ & - & ? & $80 \%$ & $90 \%$ \\
\hline $4 a$ & $4 \mathrm{a}$ & 4a & $4 \mathrm{a}$ & - & & $4 a$ & $4 \mathrm{a}$ \\
\hline $4 \mathrm{k}$ & $4 \mathrm{k}$ & $4 \mathrm{k}$ & $4 c, 4 d$ & - & $?$ & $4 \mathrm{k}$ & - \\
\hline 5 & $0.2 \%$ & - & - & - & $?$ & - & - \\
\hline
\end{tabular}

GNI, gross national income. PPP, purchasing power parity. HDI, human development index. HI, high income. LMI, lower middle income. LI, low income.

many regions, particularly parts of sub-Saharan and North Africa, partly because the public health importance of $\mathrm{HCV}$ infection has been recognized only recently [7].

In North Africa, accurate assessment of the burden of hepatitis $\mathrm{C}$ infection is hampered by the lack of adequate surveillance and by poor resources for proper data collection and management. Despite the geographic proximity of these countries and longstanding interaction between them, the prevalence and complications of HCV are greatly different between them. According to current estimates, the lowest prevalence of the virus is in Libya (0.9-1.6\%) and the highest is in adjacent Egypt (12.5-26.6\%) [8]. This review aims to navigate the reported epidemiology of $\mathrm{HCV}$ in the region of North Africa to describe the prevalence of HCV in each country, highlight the predisposing factors, and outline the strategies needed to halt the spread of HCV and its consequences.

\section{Geoepidemiological Considerations}

The North African region houses about 23\% of the African population. It is divided into two subregions, the Maghreb (Algeria, Libya, Morocco, Tunisia, and Mauritania) and the Nile valley (Egypt and Sudan). Egypt is a transcontinental country because its Sinai Peninsula lies in western Asia. North Africa also includes a number of Spanish possessions (Ceuta and Melilla, part of coast of Morocco). Despite the similarities between these countries in environment, population genetics, social customs, and habits, they differ greatly in the infrastructure of their healthcare systems, per capita income, level of urbanization, and degree of poverty. Their populations vary from poor nomadic Bedouins scattered in the Sahara areas of Mauritania, Algeria, Morocco, and Sudan to sheltered valleys in the Atlas Mountains, the Nile Valley, and delta, up to urbanized cities on the Mediterranean coast such as Tripoli and Benghazi. Epidemiological information on $\mathrm{HCV}$ among these populations is fragmentary and obtaining more information is hampered by poverty, ignorance, and more recently uprisings and conflicts [9].

With the exception of Libya, Egypt, and Morocco, North African countries lack adequate surveillance studies on hepatitis $C$ virus to enable them to take evidence-based policy decisions [10-12]. Their data are outdated, aggregated, or limited to small specific populations and affected by selection bias because most of their studies are generally based on risk groups or blood donors, and information on children and the elderly is generally not included $[10,13]$. In North Africa, predisposing factors and epidemiological information on HCV vary significantly from one country to another. Moreover, there is considerable variation in the economic and demographic situations in these countries (Table 1). Therefore, the assumption of "epidemiological homogeneity" cannot be easily adopted because it may lead to inaccurate 


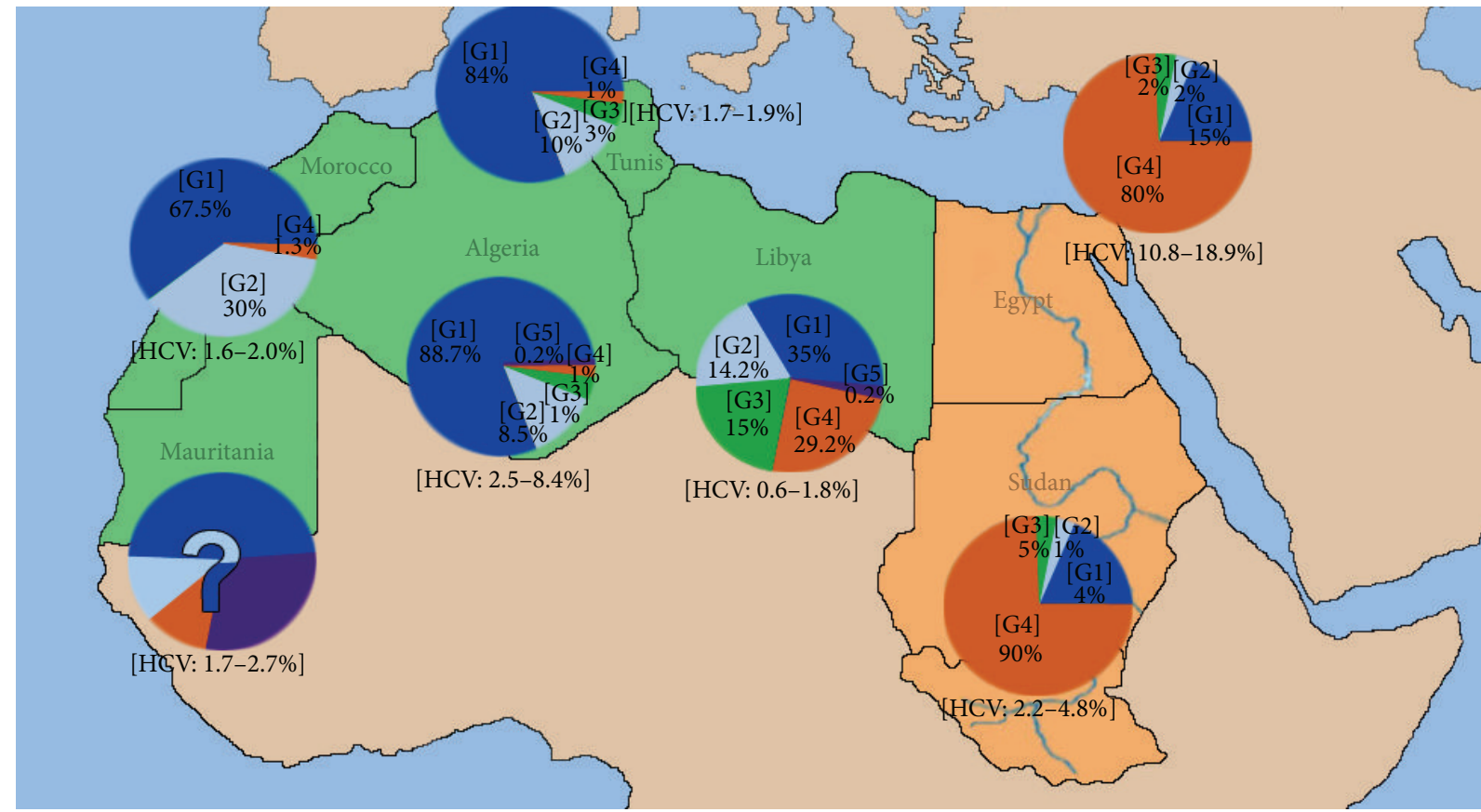

FIGURE 1: Geographic distribution of HCV genotypes among HCV-infected individuals in North Africa. G1, G2, G3, G4, and G5 refer to the respective genotypes of $\mathrm{HCV}$.

estimates of HCV seroprevalence in these countries [14]. Hence then, the epidemiological features of HCV in each country should be considered separately. The region's contribution to the global literature on HCV remains relatively small, though the number of publications from Egypt, Libya, and Morocco has increased. Figure 1 shows the prevalence of HCV and genotype distribution in all the North African countries.

\section{Epidemiology of $\mathrm{HCV}$ in the Maghreb Region}

3.1. Libya. Libya is the richest country in North Africa. It is also the second largest and has a small population. HCV is well documented in this country and major studies were carried out on all aspects of HCV infection over the last 20 years [15]. The largest comprehensive national study in Asia and Africa was carried out in Libya and covered over $1 \%$ of the total population [11]. The overall prevalence rates of $\mathrm{HCV}$ in males and females were similar (1.1\% and $1.3 \%$, resp.). The mean age of anti-HCV-positive individuals was $31.7 \pm 18.4$ years in females and $35.6+20.9$ years in males. The mean age of $\mathrm{HCV}$-positive individuals was significantly higher than that of anti-HCV negative individuals for both males (almost 10 -year difference) and females (7-year difference). HCV was more prevalent among single and younger individuals, and about $40 \%$ of HCV patients were less than 30 years old. The prevalence of HCV was higher among illiterate individuals (3.1\%) than among literate persons (0.9-1.1\%). Hepatitis C was most prevalent among intravenous drug users (7.4\%) and less prevalent but still substantial in those undergoing blood transfusion $(2.7 \%)$, surgical operation $(2.3 \%)$ or hospital admission (1.9\%).

The prevalence of HCV infection in Libya varied widely between hemodialysis centers from $0 \%$ to $35.9 \%$. Compared to seronegative patients, seropositive patients were younger and had been receiving dialysis for substantially longer. Follow-up showed that $7.1 \%$ of the dialysis patients seroconverted during the first year of dialysis [16].

A total of 20 discrete genotypes and subtypes were identified countrywide in the Libyan population, and their frequencies ranged from 11.5 to $0.3 \%$ among Libyan $\mathrm{HCV}$ patients. Genotype 4 was the most frequent among all regions (19.7-40.5\%), reaching the highest value in eastern region (27\%), followed by genotype 1 which was more prevalent in the southern (49.3\%) and western (40.0\%) regions. Genotype 3 was more prevalent in Tripoli area (21.3\%) and the eastern regions $(15.9 \%)$, while genotype 2 was common in the northern $(23.6 \%)$ and southern $(22.5 \%)$ regions $[17,18]$. The frequencies of these genotypes were significantly associated with the demographic and risk factors involved. Transmission by intravenous drug use (IVDU) has become more frequent in Libya and is associated mostly with genotype 1 (49.2\%) and genotype $3(32.6 \%)$.

3.2. Tunisia. Tunisia has the smallest area among the Maghreb countries and is bounded by the two largest countries in the region, Libya and Algeria. Different studies were carried out on HCV infection in Tunis. Two decades ago, Triki et al. studied the prevalence of hepatitis B and hepatitis $\mathrm{C}$ and delta virus infections in Tunis in a population of mainly male military recruits aged 20-25 years [19]. The overall 
prevalence of $\mathrm{HDV} / \mathrm{HCV}$ coinfection was $17.7 \%$ but it was low for HCV alone (2.7\%). In 2005, another study reported a prevalence of $\mathrm{HCV}$ of $1.7 \%$ in the general population and great heterogeneity in geographical distribution. HCV was particularly more prevalent in the northwestern region of the country than anywhere else. But there was no difference in positivity according to gender or to living in rural versus urban areas; the only significant risk factor was advanced age [20]. Similar results were reported for blood donors and diabetic patients, in whom prevalence of anti-HCV antibodies varied between $0.5 \%$ and $1.8 \%$ [21]. However, these studies suffer from lack of specificity and were confined to certain populations. They did not accurately mirror the status of HCV within the country. A recent seroprevalence study of transfusion-transmitted infections in first-time volunteer and replacement donors in Tunisia showed that HCV, according to mathematical adjusted model, reached 1.9\% (95\% CI $=0.9-4.1 P=0.11$ ) [22]. Hence, further studies are needed to assess the actual burden of $\mathrm{CV}$ infection in Tunisia.

The prevalence of HCV infection among Tunisian dialysis patients was reported to be high, reaching up to $51 \%$. There was a close correlation between the number of anti-HCVpositive patients and the duration of dialysis therapy [23, 24]. This indicates the nosocomial transmission of HCV in dialysis units where the number of infected patients is high and where the management of material does not take into account the patient's viral status.

The reported genotype patterns among Tunisians vary substantially from one study to another. Subtype $1 \mathrm{~b}$ was the most common (79\%), whereas types 1a, 2a, 2b, 3a, and 4a occurred much less frequently. Furthermore, subtype $4 \mathrm{k}$ seems to have disappeared in Tunis city in conjunction with the emergence of a new subtype of HCV4 $[25,26]$.

3.3. Algeria. Algeria is the largest country in North Africa and its population lives a range of traditional/rural or modern/urban lifestyles. Data on the epidemiology of HCV in Algeria are scarce. Official data point to a current hepatitis $\mathrm{C}$ epidemic [27], and the Algerian Ministry of Health estimated that the prevalence of $\mathrm{HCV}$ infection had reached 2.5\% [28, 29].

Seroprevalence rates of $\mathrm{HCV}$ reaching $53 \%$ were reported in patients undergoing hemodialysis and $31.6 \%$ among hemophilia patients in Algeria. This situation is plausibly connected with nosocomial transmission and occupational exposure to HCV among healthcare workers [29].

In a rare retrospective study, Rouabhia et al. investigated hepatitis $\mathrm{C}$ virus markers in 739 diabetic and 580 nondiabetic patients attending the internal medicine department of the University Hospital Center of Batna in Algeria [30]. AntiHCV seropositivity was $17.5 \%$ in diabetic patients and $8.4 \%$ in nondiabetic patients $(P<0.01)$. However, after adjustment for age, this difference is statistically significant only in patients aged $40-65$ years $(22.2 \%$ versus $9.3 \%, P=0.024)$. Despite the ongoing controversy being whether diabetes mellitus is a risk factor for HCV infection or HCV is a risk factor for type 2 diabetes mellitus, the prevalence of $\mathrm{HCV}$ among healthy Algerian in this age group is indeed high (8.49.3\%) [30].

In Algeria, $\mathrm{HCV}$ genotype 1 was the most frequent (88.7\%), followed by genotypes $2(8.5 \%), 4(1.1 \%), 3(0.9 \%)$, and $5(0.2 \%)$. The genotype distribution was related to age and region. Genotype 1 was significantly less frequent in the $\geq 60$-year age group than in younger people (OR $=0.2 ; 95 \%$ CI: $0.1-0.5, P<0.001)[27,30]$. Furthermore, genotype 1 was more frequent in the central part of the northeastern region of Algeria than elsewhere.

3.4. Morocco. Morocco is the western bounding arm of the Maghreb region, facing both the Atlantic Ocean and the Mediterranean Sea. Different studies were carried out on $\mathrm{HCV}$ in Morocco both in the general population and on higher risk groups. Early studies estimated that the prevalence of $\mathrm{HCV}$ was $1.93 \%$ in the general population and $1.08 \%$ in blood donors [31]. A recent nationwide cross-sectional survey carried out in 100 major Moroccan regions over a period of six years showed that the overall prevalence of $\mathrm{HCV}$ infection in the general population was $1.58 \%$, and it was lower among blood donors [10]. The prevalence was higher among males $\leq 30$ years old. Factors significantly associated with $\mathrm{HCV}$ infection were increasing age, dental treatment, use of glass syringes, and history of surgery. Emerging data suggest that differences in anti-HCV prevalence may exist between the northern and southern regions in Morocco [32]. $\mathrm{HCV}$ is a major problem in hemodialysis centers in Morocco. A multicenter study covering different Moroccan dialysis centers found that the prevalence varied from $11 \%$ to $91 \%$ [33].

Practitioners of traditional medicine and barbers play an important role in the spread of $\mathrm{HCV}$ in Morocco. A survey of anti-HCV antibodies among barbers and their clients indicated that the prevalence rate hovered above $5 \%$, probably because of unsanitary conditions [34]. This problem could also exist in Libya, where most of the hairdressers are Moroccans.

Drug addiction is a serious problem in Morocco and has been considered to be a "male-associated habit" because the overwhelming majority of drug addicts are young males who are either single or divorced. HCV seroprevalence is high among this group, reaching up to $60 \%$ [35].

The commonly reported $\mathrm{HCV}$ genotypes in Morocco were genotypes $1(46 \%)$ and $2(40 \%)$, followed by genotypes 3 and 4 . Among intravenous drug users, genotype 1 accounted for $65 \%$ of the cases, followed by genotype 3 (26\%) and genotype $4(10 \%)$ [36].

3.5. Mauritania. Mauritania is a Saharan country characterized by a very high prevalence of viral hepatitis that poses a serious public health problem. In a recent coherent study, up to $20 \%$ of consulting patients and pregnant women or blood donors have HBV, and up to $33 \%$ have HDV [37]. Despite the limited published data on HCV in Mauritania, HCV seems to be more prevalent in Mauritania than in other Maghreb countries. Mansour et al. conducted a comprehensive prospective study on 1966 individuals and 
showed that the overall prevalence of HBsAg was $18.3 \%$. The prevalence was significantly higher in males $(24.4 \%)$ than in females $(13.8 \%)[P<0.001$; OR: $2.04(1.46-2.85)$, $P<0.001]$. It varied significantly among the different ethnic groups: $22.7 \%$ in white Moors, $19.7 \%$ in black Moors, and $12 \%$ in African ethnicities $[P<0.025$, OR: $0.47(0.26-0.82)$, $P<0.008]$ for the comparison between White Moors and other African ethnic groups [38,39]. The characteristics of individuals positive for HBsAg strongly suggest healthcareassociated transmission, intrafamilial transmission, sexual transmission, more frequently a history of hospitalization, and transmission through iatrogenic, medical, or paramedical procedures.

In 2000, 2854 healthy blood donors were screened for HCV antibodies at the National Hospital of Nouakchott, and the prevalence of $\mathrm{HCV}$ was found to be $2.7 \%$, but no risk factors were studied [40,41]. However, it has been speculated that the prevalence of HCV in Mauritania may be as high as $10.7 \%$, similar to that in West African countries [8].

\section{Epidemiology of $\mathrm{HCV}$ in the Nile Valley Region}

HVC prevalence in the Nile Valley region has unique features and specific epidemiological characteristics that have implications for the prevention and future prospects of $\mathrm{HCV}$ in the region.

4.1. Egypt. Egypt is confronted with a huge HCV infection problem that distinguishes it from the rest of North Africa. It has the highest prevalence of $\mathrm{HCV}$ in the world, and $\mathrm{HCV}$ infection and its complications are among the leading public health challenges in the country [40]. The epidemiological and clinical status of HCV in Egypt is well known and different studies were carried out to examine the different aspects of this epidemic [41]. Data on HCV in Egypt are diverse and vary greatly from one study to another. Nevertheless, they all reach the same conclusion that the prevalence of $\mathrm{HCV}$ is very high among all groups and populations $[42,43]$.

A major survey conducted in 2008 reported a HCV prevalence of $14.7 \%$ in a nationally representative sample of 11,126 Egyptians aged 15-59 years. The infection rate increased steadily with age. It was nearly zero in children under the age of 9 years, 5\% among those aged $30-39$ years, and $10 \%$ among those aged $\geq 50$ years [12]. The study also showed that rural villages had a higher prevalence than urbanized cities [44]. Studies conducted in the Nile delta region, Assuit and Benha, showed a higher prevalence among all sectors studied, including pregnant women and children [45].

Overall, the average HCV prevalence among risk groups is even higher. It was reported to be $38 \%$ among schistosomiasis patients, $63.0 \%$ among intravenous drug users, and $46.1-100 \%$ among hemodialysis patients. Population groups at an intermediate risk of exposure include diabetic patients, hospital outpatient attendees, hospitalized patients, household contacts of index cases (HCV-positive cases), patients with sexually transmitted infections, patients with periodontal disease, prisoners, and healthcare workers [46, 47].

HCV genotype 4 (subtype 4a) predominates in Egypt and is responsible for $>90 \%$ of the infections; the rest of the infections are due to genotype $1(\mathrm{lb}, 1 \mathrm{~g})$ and genotype $3(3 \mathrm{a})$ [48]. Recent data show that the overall prevalence of HCV in Egypt is declining as those who were initially infected are aging and dying. However, the disease burden of HCV and associated costs will continue to grow due to the increasing number of individuals developing advanced liver disease and dying from liver pathologies related to HCV rises [49].

4.2. Sudan. Sudan is the largest country in the Nile valley with a land mass about the size of Europe. It has been engaged in an ongoing civil war for 20 years, and one of the consequences is about 4 million refugees [50]. The Sudanese community is characterized by great social and demographic diversity reflected in the epidemiology of microbial diseases in the country. Studies on HCV in Sudan are few and lack specific national goals. The few studies on $\mathrm{HCV}$ infection in Sudan demonstrated a seroprevalence ranging from 2.2\% in the Gezira state, in which schistosomiasis is endemic, to $4.8 \%$ in patients with schistosomal periportal fibroses [51]. The prevalence of HCV infection among asymptomatic male Sudanese blood donors was $4.4 \%$, but females do not donate blood in Sudan. Other studies reported prevalence rates of $3 \%$ and $1.5 \%$ in southern and northern regions of Sudan, respectively. Furthermore, HCV transmission was evident in healthcare settings, and occupational risk is expected to be high. In presurgery screened patients in Khartoum, central Sudan, prevalence of HCV was $2 \%$ [52].

Unprotected sexual activity (20\%) was the most apparent predisposing risk factor for HCV seroreactors, followed by razor sharing (13.3\%), parenteral drug injection (10\%), tattooing, and surgical procedures. The highest prevalence of $\mathrm{HCV}$ infection in Sudan was noted in patients with end-stage renal disease who were on regular hemodialysis (seroprevalence of $66.7 \%)[52,53]$. Major risk factors for infection were longer duration of dialysis, dialysis in multiple centers, and an age over 30 years. Genotype 4 was the most frequently isolated genotype among HCV-positive patients in Sudan [53].

Studies on the HCV status among intravenous drug users and HIV patients in Sudan are lacking. Recently, Sudanese researchers raised the importance of this issue, particularly as Sudan borders nine African countries on the east and the south that have some of the highest HIV-1 infection rates in the world [54]. The HCV status in Sudan is not well documented, particularly for high risk groups and in healthcare settings. Further studies are urgently needed, including but not limited to population-based studies that are representative of entire communities, and a national cooperative registry system should be established.

\section{Vectors of HCV Transmission in the North Africa}

5.1. Drug Trafficking. Drug trafficking poses specific problems for North African countries, and it is exacerbated by 
the geographical location and the vast area of the region. Morocco is the world's foremost producer of cannabis resin and remains the main source of the drug for the consumer markets in Western Europe; the largest seizure in 2007 was in Mauritania [55, 56]. Studies from the Middle East and North Africa regions indicate that after Iran, the largest numbers of people injecting drugs are in Egypt and Algeria [57]. Illicit drug injection is also a significant route of HIV transmission in Libya and Tunisia, as well as in Sudan. Cocaine use is reportedly increasing in these countries, but cocaine injection has not been reported. Use of noninjectable drugs has not been shown to be linked to the transmission of HIV or HCV. Information on HCV prevalence among people who inject drugs is not available for most countries in the region, but, where reported, the data reveal high levels of HCV infection [58]. Furthermore, men who have sex with men and people who inject drugs are both highly criminalized populations in region and they are more affected by HCV and HIV than the rest of the population [59].

5.2. Urbanization Level. Urbanization has contributed to an overall improvement of health status [60]. Different studies have shown that the level of urbanization could influence the prevalence of HCV in the North African region. Libya, which is considered an urbanized country, has the lowest $\mathrm{HCV}$ prevalence. The other countries are mainly rural and are not expected to pass the urban tipping point before 2050 [61]. Sociodemographic studies comparing rural with urban Egyptian populations have shown a higher prevalence among rural populations [62]. Blood donors and children from rural areas had a higher prevalence of HCV than those from urban areas [63]. Similar results were reported for hepatocellular carcinoma in rural and urban areas [48]. The same pattern was reported in Tunisia, Algeria, and Morocco. $\mathrm{HCV}$ prevalence was significantly higher in the northwestern region of Tunisia and the suburban area of Tunis than in the northern region. In Algeria, HCV infection was strongly associated with living in remote mountains or desert regions as compared to living in urbanized environments along the Mediterranean coast [27]. In Morocco, being a rural resident was found to be strongly associated with HCV infection. In Mauritania and Sudan, the vast majority of the population is composed either of rural dwellers or Bedouins even within the surroundings the capital cities. This could be attributed to the habits and economic status of this major subpopulation. Lack of sanitary services, illiteracy, traditional medicine practice, and occupational hazards and not adopting safe medical practices may contribute to higher levels of $\mathrm{HCV}$ infection. However, further studies are needed to verify this assumption.

5.3. Medical Practices and Personal Habits. Hemodialysis, blood transfusion, and practices associated with hospital care, combined with social or personal habits and other community-associated factors, are among the most important risk factors for $\mathrm{HCV}$ in North African countries. Mortality and morbidity due to infections associated with such factors are expected to be high, and the adjusted hazard ratio for patient death may reach 2.3 [64]. The prevalence of HCV infections observed in blood products and dialysis patients in these countries are much higher than in the general population. This situation is worsened in areas of chronic conflict, such as Sudan and the Sahara region, as well as in regions newly gripped by war, notably Libya, in which blood supplies were safer and more secure before the 2011 uprising. Tunisia and Libya experienced stock-outs during their recent uprisings both for blood screening reagents and for access to new antiretroviral drugs. The impact of these conflicts on the healthcare system should be evaluated [65]. Healthcare workers should be sufficiently informed about the risk of acquiring $\mathrm{HCV}$ via sharp injuries and other nosocomial routes. Habits and cultural factors that may influence the spread of HCV in North African countries include male and female circumcision, particularly in Egypt, Sudan, Mauritania, and Morocco. Hijiama (bloodletting) done by informal practitioners, tattooing, folk body piercing and threading, sharing hygiene tools and sharp items, and the use of communal barbers may be considered as risk factors for HCV, particularly among rural dwellers [21, 34]. Education and public awareness campaigns are needed to teach the populations about the risks involved.

5.4. HCV/HIV Coinfection. There is little information on $\mathrm{HCV} / \mathrm{HIV}$ coinfection in North African countries. The paucity of information on injecting drug use and HIV in these countries could be attributed to the reluctance to commission research or publicize information on these two highly stigmatized issues, and such avoidance could mask the true extent to which people who inject drugs are affected by HIV [66]. The reported prevalence rates of HCV/HIV coinfection vary depending on the route of transmission. Morocco is the only country in the region that has reliable surveillance programs for HIV. Prevalence of $\mathrm{HIV} / \mathrm{HCV}$ coinfections in Morocco was reported to be about $20 \%$ among injecting drug users and sex workers, but it was $10.6 \%$ among patients of different socioeconomic backgrounds [35].

Women have already overtaken men in their contribution to the HIV epidemic in Sudan, Algeria, and Tunisia, where the number of AIDS cases is higher in women than in men. In Morocco, the situation is becoming increasingly feminized [67]. A study carried on 4220 female sex workers aged 1549 years recruited from 14 states in Sudan indicated that the prevalence of HIV ranged from 4.4 to $23.9 \%$, with $6 \%$ coinfected with HCV [67]. In Tunisia, the prevalence rate of anti-HCV positivity was $40 \%$ among HIV-infected patients, of whom $78 \%$ were injecting drugs. In Libya, over $90 \%$ of HIV cases are attributable to injecting drugs. A populationbased study in nine districts in Tripoli showed that the average prevalence rates of HIV reached $0.2 \%$, whereas $\mathrm{HBV}$ and HCV rates reached $3.7 \%$ and $0.9 \%$, respectively [68]. In Egypt, the rate of HIV infection among female sex workers was much higher (up to $36.3 \%$ ) than among women who do not sell sex [69]. Furthermore, a randomized detailed survey in 2010 found that $6.8 \%$ of intravenous drug users in 


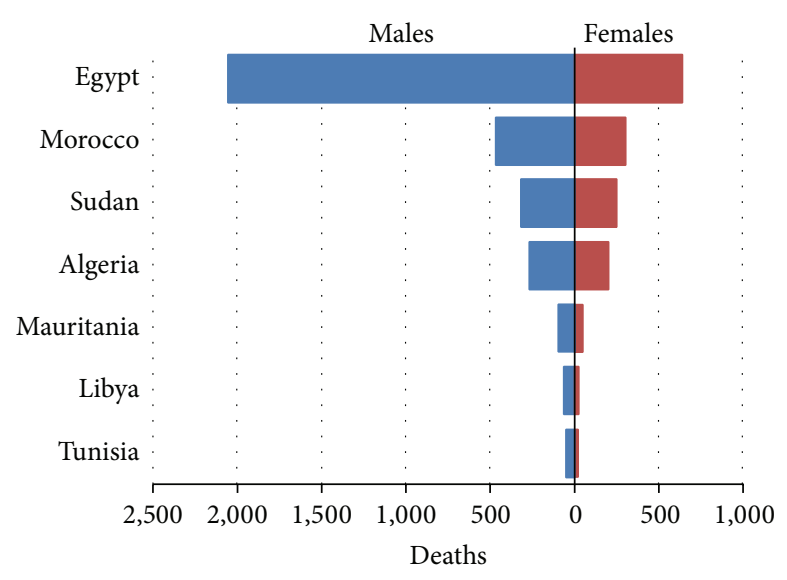

(a)

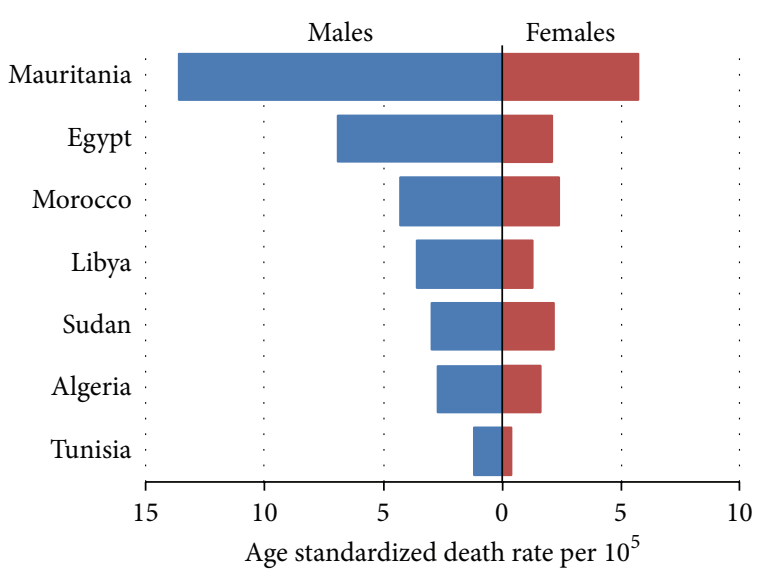

(b)

Figure 2: Mortality from HCV-associated hepatocellular carcinoma in North Africa.

Cairo and 6.5\% in Alexandria were infected with HIV [70]. HCV coinfection among these populations ranged from 37 to $86 \%$ in Egypt. The coemergence of HCV in HIV infected patients has become a serious problem in the North African region: effective preventive and monitoring programs have to be implemented [70].

5.5. Miscellaneous Factors. Various other factors could contribute to the epidemicity of HCV in North Africa, including imprisonment, alcoholism, and sex practices, which are stigmatized socially and culturally. The situation is exacerbated by lack of human rights, injustice, and the recent political uprisings in this region. More than a third of all prisoners and more than $80 \%$ of injecting drug users were positive for antibodies to hepatitis $\mathrm{C}$ virus in North African countries [13]. Libya is the only country in the region for which there is an available estimate of the number of prisoners with a history of injecting drug use (approximately 60\%) [71]. Alcohol drinking and female sex work are other factors in North African countries. Alcohol consumption accelerates the course of chronic hepatitis C. In Mauritania and Libya alcohol consumption and prostitution are banned according to Islamic laws. Recorded alcohol consumption rates are variable across North Africa. Sudan has low levels of alcohol consumption. On the other hand, Morocco, Egypt, Algeria, and Tunis have higher consumption rates [56, 72]. HCV and other associated sexually transmitted diseases are rarely studied in North African countries, leaving only hypothetical speculation. The only formulated and well planned study was done in Sudan [67]. Biobehavioral surveys using respondentdriven sampling were carried out among female sex workers in the capital cities of 14 states in Sudan in 2011-2012. The findings point to a high burden of sexually transmitted diseases in female sex workers [67]. The highest prevalence of $\mathrm{HCV}$ was found in the western zone $(2.6 \%$ and $5.1 \%$ at two sites). However, there is little information on the prevalence of HCV among injection drug users. Hence, further studies are needed.

\section{Consequences of HCV in North Africa}

Hepatitis C infection has been implicated in the development of hepatocellular carcinoma (HCC) in North African countries. A multicenter study of the risk factors for hepatocellular carcinoma was carried out in cooperation between Morocco, Algeria, and Tunisia. The study showed that over $60 \%$ of HCC patients were positive for anti-HCV, though only $17.9 \%$ and $19 \%$ were positive for HBsAg or had diabetes, respectively [73], A33-fold higher in HCV infection comparable by just 10 -fold for HBV. However, the association was mainly for HCV genotypes 1 and 2. Egypt had by far the highest burden of deaths from HCV-associated HCC, and 63.3\% of all HCV-associated HCC deaths occurred in Egypt (Figure 2(a)), followed by Morocco, Sudan, and Algeria. The figures were lower for Libya and Tunisia. Mauritania and Egypt also had the highest age-standardized rates deaths (ASDR) for HCV-associated HCC in both males and females (Figure 2(b)) [74]. There is no easy and effective treatment for HCC, so preventing the transmission of hepatitis viruses is the most important step to reduce the risk of HCC in these countries. Extrahepatic diseases also cause morbidity among $\mathrm{HCV}$-infected individuals. Patients with chronic hepatitis C have a higher risk of developing diabetes, thyroid disease, lichen planus, and an array of neuropsychiatric disorders $[75,76]$. These conditions are rarely studied in the region of North Africa.

Though the rates of HCV infection are declining, particularly in Libya and Egypt, the decline has not yet met the expectations. Forecast studies are rarely done in North Africa. In Libya, Daw and his collaborators designed a mathematical model based on data collected from blood donors to predict the future status of HCV in the country [77]. The data show a stationary phase of $\mathrm{HCV}$ prevalence in the coming ten years. If preventive measures are applied, the prevalence will become very low within 50 years (Figure 3(a)). In Egypt, strategies have been built to increase diagnosis and treatment. Coupled with measures to prevent transmission, the result would be to control the disease and markedly reduce the 


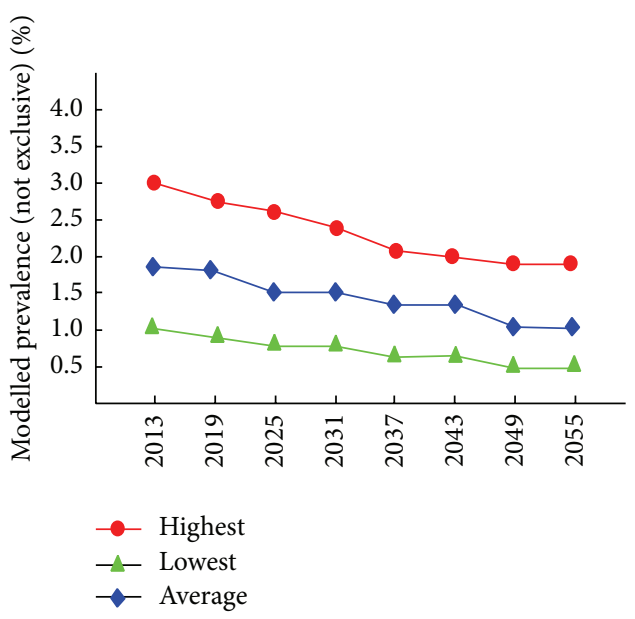

(a) Libya

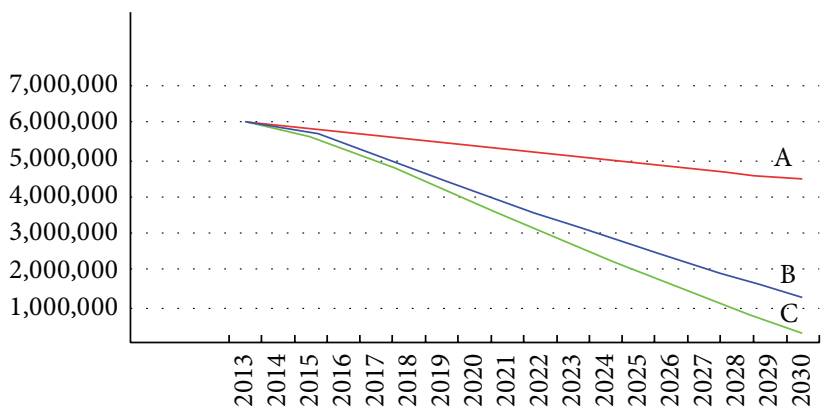

(b) Egypt

FIGURE 3: The impact of prevention and treatment on future prevalence rates of HCV. Modeled prevalence of hepatitis C virus infection Libya and Egypt. A: number of HCV-infected cases. B: number of cases after prevention. C: number of cases after prevention and treatment.

prevalence and burden of HCV in the country by 2030 (Figure 3(b)) [78].

\section{Conclusion}

North African countries face a serious hidden crisis of $\mathrm{HCV}$ infections complicated by ignorance and inefficiency of public healthcare services and coupled with lack of research studies and programs for monitoring HCV infection. Countries such as Mauritania, Algeria, and Sudan should expand their efforts to address the emerging HCV epidemic among their populations. A multifaceted approach is needed. Regional and national guidelines for screening, treating, and preventing HCV infection should be endorsed and adopted by healthcare authorities and providers. Infected individuals and those who are at a higher risk should be provided with easy access to healthcare services. Implementation of advanced research and strengthening the practices of data collection and reporting of $\mathrm{HCV}$ infections should be given priority in the region of North Africa [79, 80].

\section{Disclosure}

This research was done in association with the Libyan Study Group of Hepatitis \& HIV.

\section{Competing Interests}

The authors declare that they have no conflict of interests.

\section{Authors' Contributions}

All the authors contributed substantially to the study and read and approved the final paper.

\section{Acknowledgments}

The authors are deeply grateful to the Libyan Study Group of Hepatitis \& HIV and to the Department of Medical Microbiology and Immunology, Faculty of Medicine, Tripoli, Libya, for their assistance, and particularly those who helped to analyze and critically review the data published here. Special thanks go to Dr. Amin Bredan, http://www.theeditor.be/, for his professional editing of the paper.

\section{References}

[1] D. L. Thomas, "Global control of hepatitis C: where challenge meets opportunity," Nature Medicine, vol. 19, no. 7, pp. 850-858, 2013.

[2] J. Lazarus, Global Policy Report on the Prevention and Control of Viral Hepatitis in Who Member States, World Health Organization, Geneva, Switzerland, 2014.

[3] V. Madhava, C. Burgess, and E. Drucker, "Epidemiology of chronic hepatitis $\mathrm{C}$ virus infection in sub-Saharan Africa," The Lancet Infectious Diseases, vol. 2, no. 5, pp. 293-302, 2002.

[4] C. A. Onyekwere and L. Hameed, "Hepatitis B and C virus prevalence and association with demographics: report of population screening in Nigeria," Tropical Doctor, vol. 45, no. 4, pp. 231-235, 2015.

[5] H. S. Te and D. M. Jensen, "Epidemiology of hepatitis B and C viruses: a global overview," Clinics in Liver Disease, vol. 14, no. 1, pp. 1-21, 2010.

[6] F. Negro and A. Alberti, "The global health burden of hepatitis C virus infection," Liver International, vol. 31, no. 2, pp. 1-3, 2011.

[7] J.-M. Pawlotsky, "New hepatitis C therapies: the toolbox, strategies, and challenges," Gastroenterology, vol. 146, no. 5, pp. 11761192, 2014.

[8] J. Riou, M. Aït Ahmed, A. Blake et al., "Hepatitis C virus seroprevalence in adults in Africa: a systematic review and metaanalysis," Journal of Viral Hepatitis, vol. 23, pp. 244-255, 2016. 
[9] M. A. Daw, A. El-Bouzedi, and A. A. Dau, "Libyan armed conflict 2011: mortality, injury and population displacement," African Journal of Emergency Medicine, vol. 5, no. 3, pp. 101-107, 2015.

[10] W. Baha, A. Foullous, N. Dersi et al., "Prevalence and risk factors of hepatitis B and C virus infections among the general population and blood donors in Morocco," BMC Public Health, vol. 13, article 50, 2013.

[11] M. A. Daw and A. El-Bouzedi, "Prevalence of hepatitis B and hepatitis $C$ infection in Libya: results from a national population based survey," BMC Infectious Diseases, vol. 14, article 17, 2014.

[12] J. Guerra, M. Garenne, M. K. Mohamed, and A. Fontanet, "HCV burden of infection in Egypt: results from a nationwide survey," Journal of Viral Hepatitis, vol. 19, no. 8, pp. 560-567, 2012.

[13] M. A. Daw and A. A. Dau, "Hepatitis C virus in Arab world: a state of concern," The Scientific World Journal, vol. 2012, Article ID 719494, 12 pages, 2012.

[14] M. A. Daw, "Transmission of hepatitis C Virus," in Hepatitis C Virus: Molecular Pathways and Treatments, O. Stambouli, Ed., OMICS Group, Henderson, Nev, USA, 2014.

[15] M. A. Daw, M. A. Elkaber, A. M. Drah, M. M. Werfalli, A. A. Mihat, and I. M. Siala, "Prevalence of hepatitis C virus antibodies among different populations of relative and attributable risk," Saudi Medical Journal, vol. 23, no. 11, pp. 1356-1360, 2002.

[16] W. A. Alashek, C. W. McIntyre, and M. W. Taal, "Hepatitis B and $\mathrm{C}$ infection in haemodialysis patients in Libya: prevalence, incidence and risk factors," BMC Infectious Diseases, vol. 12, article 265, 2012.

[17] M. A. Daw, A. El-Bouzedi, and A. A. Dau, "Geographic distribution of HCV genotypes in Libya and analysis of risk factors involved in their transmission," BMC Research Notes, vol. 8, article 367, 2015.

[18] H. A. Elasifer, Y. M. Agnnyia, B. A. Al-Alagi, and M. A. Daw, "Epidemiological manifestations of hepatitis $C$ virus genotypes and its association with potential risk factors among Libyan patients," Virology Journal, vol. 7, article 317, 2010.

[19] H. Triki, N. Said, A. B. Salah et al., "Seroepidemiology of hepatitis B, C and delta viruses in Tunisia," Transactions of the Royal Society of Tropical Medicine and Hygiene, vol. 91, no. 1, pp. 11-14, 1997.

[20] S. Mejri, A. Ben Salah, H. Triki, N. Ben Alaya, A. Djebbi, and K. Dellagi, "Contrasting patterns of hepatitis $\mathrm{C}$ virus infection in two regions from Tunisia," Journal of Medical Virology, vol. 76, no. 2, pp. 185-193, 2005.

[21] N. Kaabia, E. Ben Jazia, I. Slim et al., "Association of hepatitis C virus infection and diabetes in central Tunisia," World Journal of Gastroenterology, vol. 15, no. 22, pp. 2778-2781, 2009.

[22] R. Ben Jemia and E. Gouider, "Seroprevalency of transfusiontransmitted infections in first-time volunteer and replacement donors in Tunisia," Transfusion Clinique et Biologique, vol. 21, no. 6, pp. 303-308, 2014.

[23] R. Debbeche, Y. Said, H. Ben Temime et al., "Epidémiologie de l'hépatite C en Tunisie," La Tunisie Medicale, vol. 91, no. 2, pp. 86-91, 2013.

[24] F. Sassi, Y. Gorgi, K. Ayed, T. B. Abdallah, A. Lamouchi, and H. B. Maiz, "Hepatitis C virus antibodies in dialysis patients in Tunisia: a single center study," Saudi Journal of Kidney Diseases and Transplantation, vol. 11, pp. 218-222, 2000.

[25] A. Djebbi, H. Triki, O. Bahri et al., "Genotypes of hepatitis C virus circulating in Tunisia," Epidemiology and Infection, vol. 130, no. 3, pp. 501-505, 2003.
[26] F. H. Kchouk, Y. Gorgi, L. Bouslama et al., "Phylogenetic analysis of isolated HCV strains from tunisian hemodialysis patients," Viral Immunology, vol. 26, no. 1, pp. 40-48, 2013.

[27] A. Bensalem, K. Selmani, N. Hihi et al., "Eastern region represents a worrying cluster of active hepatitis C in Algeria in 2012," Journal of Medical Virology, vol. 88, no. 8, pp. 1394-1403, 2016.

[28] National Travel Health Network Centre (NATHNAC), Country Information, Algeria, Tunisia, Morocco, 2009.

[29] Z. Ayed, D. Houinato, M. Hocine, S. Ranger-Rogez, and F. Denis, "Prevalence of serum markers of hepatitis B and C in blood donors and pregnant women in Algeria," Bulletin de la Société de Pathologie Exotique, vol. 88, no. 5, pp. 225-228, 1995.

[30] S. Rouabhia, M. Sadelaoud, K. Chaabna-Mokrane, W. Toumi, and L. Abenavoli, "Hepatitis $\mathrm{C}$ virus genotypes in north eastern Algeria: a retrospective study," World Journal of Hepatology, vol. 5, no. 7, pp. 393-397, 2013.

[31] S. Benjelloun, B. Bahbouhi, S. Sekkat, A. Bennani, N. Hda, and A. Benslimane, "Anti-HCV seroprevalence and risk factors of hepatitis C virus infection in Moroccan population groups," Research in Virology, vol. 147, no. 4, pp. 247-255, 1996.

[32] H. Boutayeb, A. Aamoum, and N. Benchemsi, "Connaissances sur les virus des hépatites B et C et le VIH chez des donneurs de sang à Casablanca," Eastern Mediterranean Health Journal, vol. 12 , no. 5, pp. 538-547, 2006.

[33] B. O. M. Abdelaali, D. Taoufik, A. Samir, and M. Saad, "Hepatitis C viral prevalence and seroconversion in Moroccan hemodialysis units: eight year follow up," Journal of Medical Diagnostic Methods, vol. 2, p. 141, 2013.

[34] I. Belbacha, I. Cherkaoui, M. Akrim, K. E. Dooley, and R. El Aouad, "Seroprevalence of hepatitis B and C among barbers and their clients in the Rabat region of Morocco," Eastern Mediterranean Health Journal, vol. 17, no. 12, pp. 911-919, 2011.

[35] R.-D. Trimbitas, F. Z. Serghini, F. Lazaar et al., "The 'hidden' epidemic: a snapshot of Moroccan intravenous drug users," Virology Journal, vol. 11, no. 1, article 43, 2014.

[36] I. Brahim, A. Akil, E. M. Mtairag et al., "Morocco underwent a drift of circulating hepatitis C virus subtypes in recent decades," Archives of Virology, vol. 157, no. 3, pp. 515-520, 2012.

[37] F. Lunel-Fabiani, W. Mansour, A. O. Amar et al., "Impact of hepatitis B and delta virus co-infection on liver disease in Mauritania: a cross sectional study," The Journal of Infection, vol. 67, no. 5, pp. 448-457, 2013.

[38] W. Mansour, M.-A. Bollahi, C.-T. Hamed et al., "Virological and epidemiological features of hepatitis delta infection among blood donors in Nouakchott, Mauritania," Journal of Clinical Virology, vol. 55, no. 1, pp. 12-16, 2012.

[39] W. Mansour, F.-Z. F. Malick, A. Sidiya et al., "Prevalence, risk factors, and molecular epidemiology of hepatitis B and hepatitis delta virus in pregnant women and in patients in Mauritania," Journal of Medical Virology, vol. 84, no. 8, pp. 1186-1198, 2012.

[40] C. Estes, M. Abdel-Kareem, W. Abdel-Razek et al., "Economic burden of hepatitis C in Egypt: the future impact of highly effective therapies," Alimentary Pharmacology \& Therapeutics, vol. 42, no. 6, pp. 696-706, 2015.

[41] D. A. Saleh, F. M. Shebl, S. S. El-Kamary et al., "Incidence and risk factors for community-acquired hepatitis $\mathrm{C}$ infection from birth to 5 years of age in rural Egyptian children," Transactions of the Royal Society of Tropical Medicine and Hygiene, vol. 104, no. 5, pp. 357-363, 2010.

[42] R. Breban, W. Doss, G. Esmat et al., "Towards realistic estimates of HCV incidence in Egypt," Journal of Viral Hepatitis, vol. 20, no. 4, pp. 294-296, 2013. 
[43] F. D. Miller, M. S. Elzalabany, S. Hassani, and D. F. Cuadros, "Epidemiology of hepatitis C virus exposure in Egypt: opportunities for prevention and evaluation," World Journal of Hepatology, vol. 7, no. 28, pp. 2849-2858, 2015.

[44] A. Medhat, M. Shehata, L. S. Magder et al., "Hepatitis C in a community in Upper Egypt: risk factors for infection," The American Journal of Tropical Medicine and Hygiene, vol. 66, no. 5, pp. 633-638, 2002.

[45] O. Okasha, A. Munier, E. Delarocque-Astagneau et al., "Hepatitis $\mathrm{C}$ virus infection and risk factors in health-care workers at Ain Shams University Hospitals, Cairo, Egypt," Eastern Mediterranean Health Journal, vol. 21, no. 3, pp. 199-212, 2015.

[46] C. R. Kenyon and R. Colebunders, "The association between female genital cutting and spousal HCV infection in Egypt," International Journal of Hepatology, vol. 2014, Article ID 164357, 10 pages, 2014.

[47] M. K. Mohlman, D. A. Saleh, S. Ezzat et al., "Viral transmission risk factors in an Egyptian population with high hepatitis $\mathrm{C}$ prevalence," BMC Public Health, vol. 15, article 1030, 2015.

[48] M. Abdel-Hamid, M. El-Daly, V. Molnegren et al., "Genetic diversity in hepatitis $\mathrm{C}$ virus in Egypt and possible association with hepatocellular carcinoma," The Journal of General Virology, vol. 88, no. 5, pp. 1526-1531, 2007.

[49] R. Breban, N. Arafa, S. Leroy et al., "Effect of preventive and curative interventions on hepatitis c virus transmission in Egypt (ANRS 1211): a modelling study," The Lancet Global Health, vol. 2, no. 9, pp. e541-e549, 2014.

[50] M. Hierholzer, R. R. Graham, I. El Khidir et al., "HIV type 1 strains from East and West Africa are intermixed in Sudan," AIDS Research and Human Retroviruses, vol. 18, no. 15, pp. 11631166, 2002.

[51] H. M. Mudawi, "Epidemiology of viral hepatitis in Sudan," Clinical and Experimental Gastroenterology, vol. 1, pp. 9-13, 2008.

[52] E. A. Osman, N. A. Abdulrahman, O. Abbass, W. H. Omer, and H. A. Saad, "Prevalence of Hepatitis B surface antigen and Hepatitis $\mathrm{C}$ virus antibodies among pre-surgery screened patients in Khartoum, Central Sudan," Journal of General and Molecular Virology, vol. 4, pp. 6-9, 2012.

[53] H. M. Y. Mudawi, H. M. Smith, I. A. Fletcher, and S. S. Fedail, "Prevalence and common genotypes of HCV infection in sudanese patients with hepatosplenic schistosomiasis," Journal of Medical Virology, vol. 79, no. 9, pp. 1322-1324, 2007.

[54] S. M. Ismail, A. A. Eisa, and F. Ibrahim, "HIV-infected people in Sudan moving toward chronic poverty: possible interventions," Journal of the Association of Nurses in AIDS Care, vol. 27, no. 1, pp. 30-43, 2016.

[55] United Nations Office on Drugs and Crime, World Drug Report, 2007, https://www.unodc.org/unodc/en/data-and-analysis/ WDR-2007.html.

[56] C. Cook and N. Kanaef, The Global State of Harm Reduction 2008: Mapping the Response to Drug-related HIV and Hepatitis C Epidemics, International Harm Reduction Association, 2008.

[57] P. K. Nelson, B. M. Mathers, B. Cowie et al., "Global epidemiology of hepatitis B and hepatitis C in people who inject drugs: results of systematic reviews," The Lancet, vol. 378, no. 9791, pp. 571-583, 2011.

[58] G. R. Mumtaz, H. A. Weiss, S. L. Thomas et al., "HIV among people who inject drugs in the Middle East and North Africa: systematic review and data synthesis," PLoS Medicine, vol. 11, no. 6, Article ID e1001663, pp. 1-30, 2014.
[59] G. Mumtaz, N. Hilmi, W. McFarland et al., "Are HIV epidemics among men who have sex with men emerging in the Middle East and North Africa?: a systematic review and data synthesis," PLoS Medicine, vol. 8, Article ID e1000444, 2011.

[60] E. Alirol, L. Getaz, B. Stoll, F. Chappuis, and L. Loutan, "Urbanisation and infectious diseases in a globalised world," The Lancet Infectious Diseases, vol. 11, no. 2, pp. 131-141, 2011.

[61] A. Malik and B. Awadallah, "The economics of the Arab Spring," World Development, vol. 45, pp. 296-313, 2013.

[62] S. Zakaria, R. Fouad, O. Shaker et al., "Changing patterns of acute viral hepatitis at a major urban referral center in Egypt," Clinical Infectious Diseases, vol. 44, no. 4, pp. e30-e36, 2007.

[63] M. A. Nafeh, A. Medhat, M. Shehata et al., "Hepatitis C in a community in upper Egypt: I. Cross-sectional survey," American Journal of Tropical Medicine and Hygiene, vol. 63, no. 5-6, pp. 236-241, 2000.

[64] M. A. Daw, A. A. Dau, and M. M. Agnan, "Influence of healthcare-associated factors on the efficacy of hepatitis C therapy," The Scientific World Journal, vol. 2012, Article ID 580216, 8 pages, 2012.

[65] M. A. Daw, A. El-Bouzedi, and A. A. Dau, "The assessment of efficiency and coordination within the Libyan health care system during the armed conflict-2011," Clinical Epidemiology and Global Health, 2015.

[66] S. Ramia, N. M. Melhem, and K. Kreidieh, "Hepatitis C virus infection in the Middle East and North Africa 'mENA' region: injecting drug users (IDUs) is an under-investigated population," Infection, vol. 40, no. 1, pp. 1-10, 2012.

[67] M. Elhadi, A. Elbadawi, S. Abdelrahman et al., "Integrated biobehavioural HIV surveillance surveys among female sex workers in Sudan, 2011-2012," Sexually Transmitted Infections, vol. 89, supplement 3, pp. iiil7-iii22, 2013.

[68] M. A. Daw, A. Shabash, A. El-Bouzedi, and A. A. Dau, "Seroprevalence of $\mathrm{HBV}, \mathrm{HCV} \& \mathrm{HIV}$ co-infection and risk factors analysis in Tripoli-Libya," PLoS ONE, vol. 9, no. 6, Article ID e98793, 2014.

[69] L. J. Abu-Raddad, K. G. Ghanem, A. Feizzadeh, H. Setayesh, J. M. G. Calleja, and G. Riedner, "HIV and other sexually transmitted infection research in the Middle East and North Africa: promising progress?" Sexually Transmitted Infections, vol. 89, supplement 3, pp. iiil-iii4, 2013.

[70] A. P. Jimenez, M. K. Mohamed, N. S. Eldin et al., "Injection drug use is a risk factor for HCV infection in urban Egypt," PLoS ONE, vol. 4, no. 9, Article ID e7193, 2009.

[71] N. S. Shalaka, N. A. Garred, H. T. Zeglam et al., "Clinical profile and factors associated with mortality in hospitalized patients with HIV/AIDS: a retrospective analysis from Tripoli Medical Centre, Libya, 2013," Eastern Mediterranean Health Journal, vol. 21, no. 9, pp. 635-646, 2015.

[72] World Health Organization, "Global Status Report on Alcohol 2004," 2004, http://www.who.int/substance_abuse/publications/global_status_report_2004_overview.pdf.

[73] O. Bahri, S. Ezzikouri, B. Alaya-Bouafif et al., "First multicenter study for risk factors for hepatocellular carcinoma development in North Africa," World Journal of Hepatology, vol. 3, no. 1, pp. 24-30, 2011.

[74] G. Khan and M. J. Hashim, "Burden of virus-associated liver cancer in the Arab world, 1990-2010," Asian Pacific Journal of Cancer Prevention, vol. 16, no. 1, pp. 265-270, 2015.

[75] V. Agnello and F. G. De Rosa, "Extrahepatic disease manifestations of HCV infection: some current issues," Journal of Hepatology, vol. 40, no. 2, pp. 341-352, 2004. 
[76] A. L. Zignego, C. Ferri, S. A. Pileri, P. Caini, and F. B. Bianchi, "Extrahepatic manifestations of Hepatitis C Virus infection: a general overview and guidelines for a clinical approach," Digestive and Liver Disease, vol. 39, no. 1, pp. 2-17, 2007.

[77] M. A. Daw, A. Shabash, A. El-Bouzedi, A. A. Dau, M. Habas, and Libyan-Study-Group-of-Hepatitis-and-HIV, "Modelling the prevalence of hepatitis $\mathrm{C}$ virus amongst blood donors in Libya: an investigation of providing a preventive strategy," World Journal of Virology, vol. 5, no. 1, pp. 14-22, 2016.

[78] I. Waked, W. Doss, M. H. El-Sayed et al., "The current and future disease burden of chronic hepatitis C virus infection in Egypt," Arab Journal of Gastroenterology, vol. 15, no. 2, pp. 45-52, 2014.

[79] M. A. Daw, A. El-Bouzedi, M. O. Ahmed, A. A. Dau, and M. M. Agnan, "Epidemiology of hepatitis $C$ virus and genotype distribution in immigrants crossing to Europe from North and sub-Saharan Africa," Travel Medicine and Infectious Disease, 2016.

[80] M. A. Daw, A. El-Bouzedi, M. O. Ahmed, A. A. Dau, M. M. Agnan, and A. M. Drah, "Geographic integration of hepatitis C virus: a global threat," World Journal of Virology (WJV), 2016. 


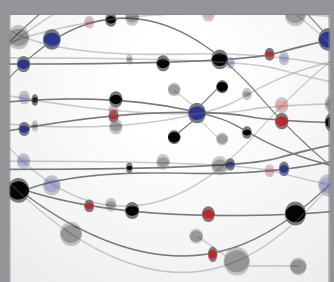

The Scientific World Journal
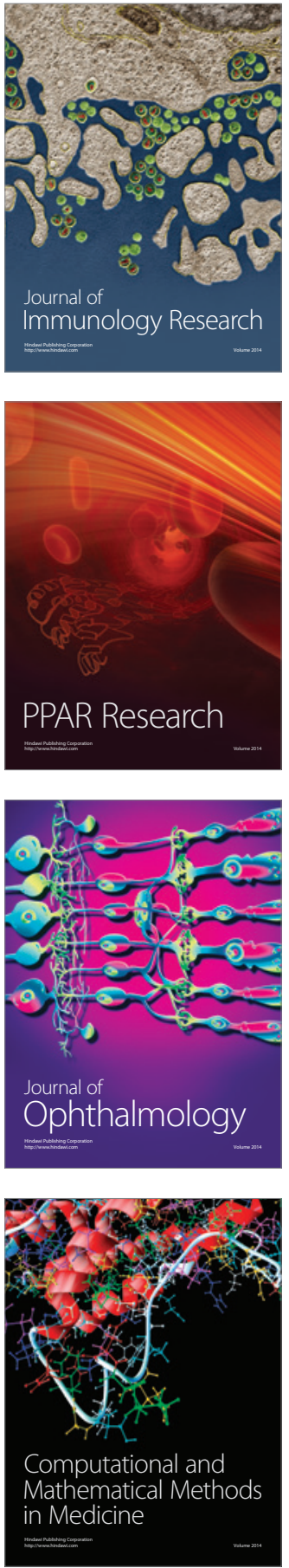

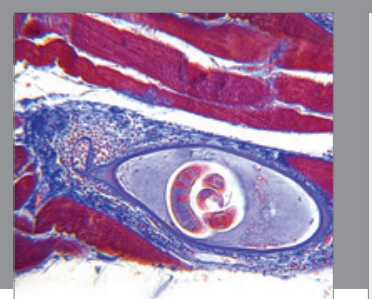

Gastroenterology Research and Practice

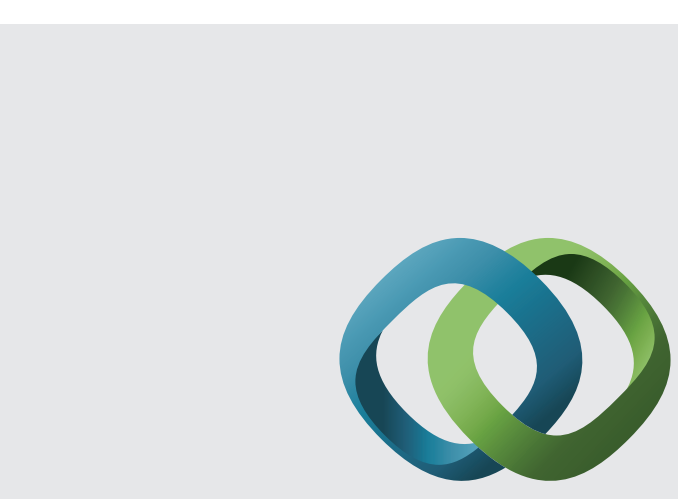

\section{Hindawi}

Submit your manuscripts at

http://www.hindawi.com
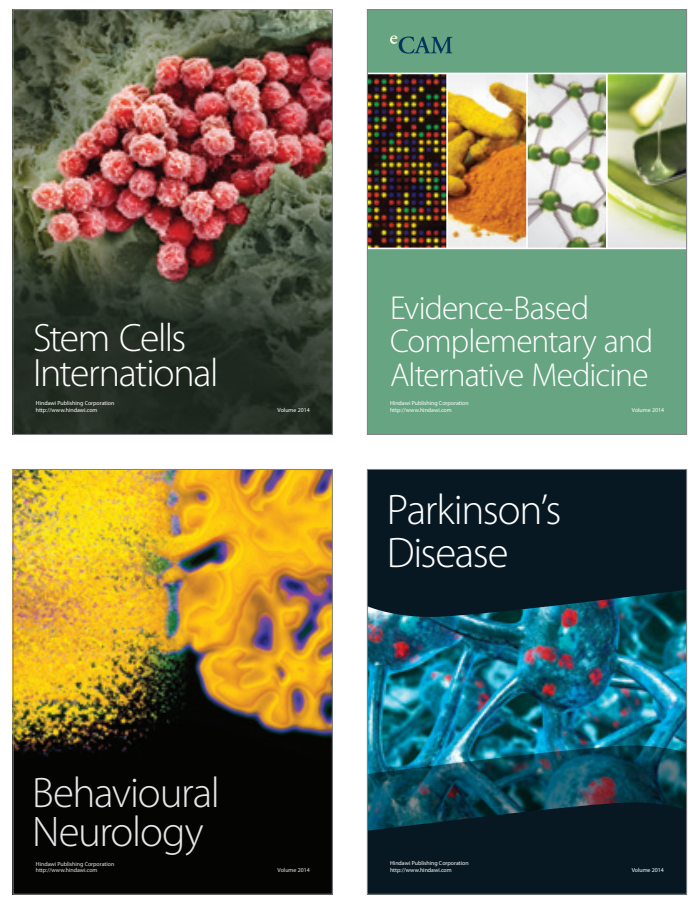
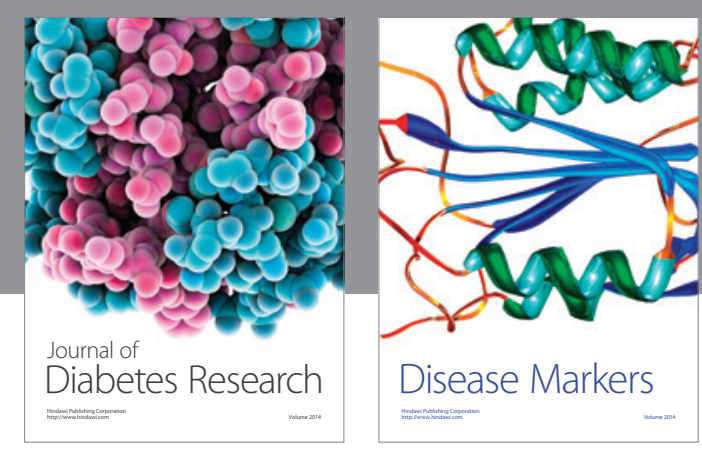

Disease Markers
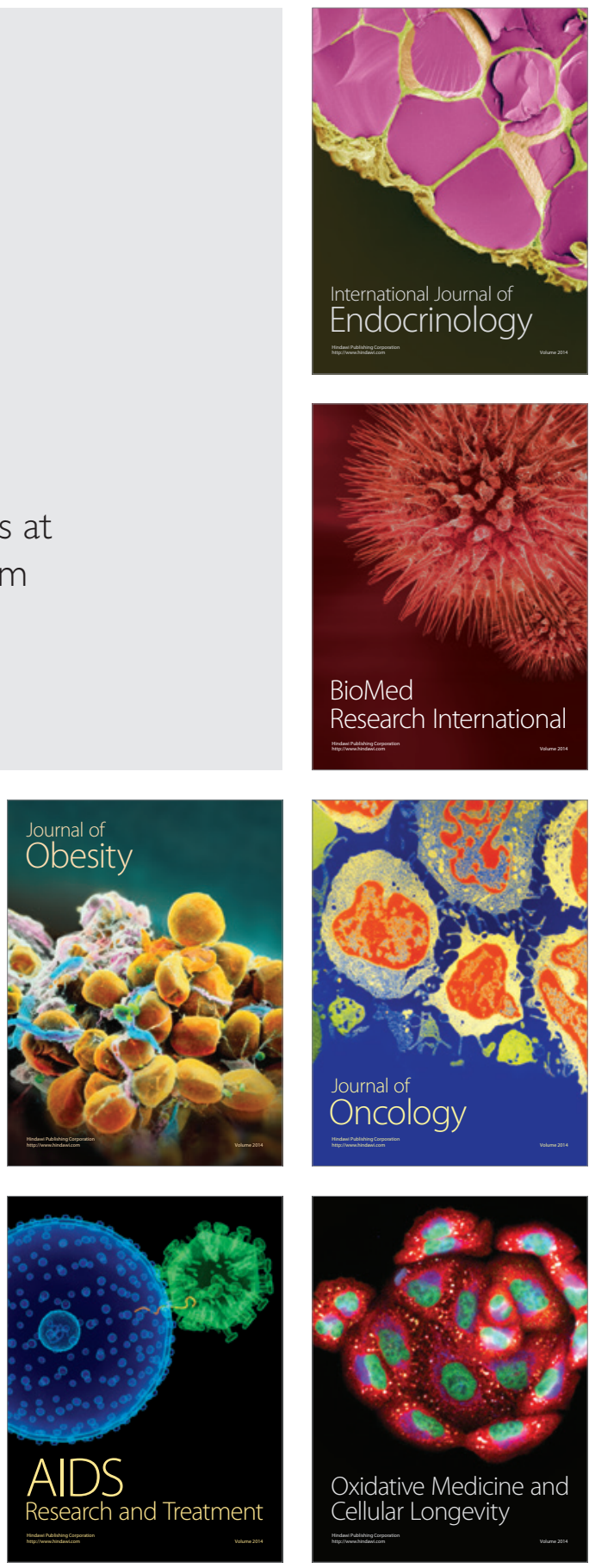